\title{
Euglena tuba extract provides protection against lipopolysaccharide-induced inflammatory response and oxidative stress in mice
}

\author{
Rashmi Kesherwani ${ }^{1} \cdot$ Raushan Kumar $^{1} \cdot$ Ujla Minhas $^{1} \cdot$ Syed Ibrahim Rizvi ${ }^{1}$ (D)
}

Received: 7 July 2020 / Accepted: 5 October 2020 / Published online: 21 October 2020

(C) Institute of Molecular Biology, Slovak Academy of Sciences 2020

\begin{abstract}
Lipopolysaccharide (LPS), an endotoxin, is known to induce inflammatory response and oxidative stress in rodents. We evaluated the protective role of Euglena tuba extract (ETME) against LPS induced inflammatory response and oxidative stress in male Balb/c mice. Male Balb/c mice were divided into 4 groups. Group 1 (control) were intraperitoneally administered $0.5 \mathrm{~mL}$ PBS. Group 2, 3 and 4 were treated with a single dose of LPS (i.p. $40 \mathrm{mg} / \mathrm{kg}$ body weight). Prior $1 \mathrm{~h}$, Group 3 and 4 received orally $100 \mathrm{mg} / \mathrm{kg}$ body weight and $200 \mathrm{mg} / \mathrm{kg}$ body weight ETME respectively. Biomarkers of oxidative stress including TBARS, SOD, Catalase, Liver marker enzyme (SGPT and SGOT), Nitric Oxide, and inflammatory cytokines including IL-6 and TNF- $\alpha$, were estimated in serum. Oxidative stress and inflammatory markers were significantly increased in the LPS treated group, whereas ETME treated group at different concentrations protected mice from pro inflammatory cytokines and oxidative stress. Our results indicate that $70 \%$ methanolic extract of Euglena tuba can efficiently counteract free radical generation and increased level of inflammatory cytokine in an LPS induced mice model.
\end{abstract}

Keywords Mice $\cdot$ Lipopolysaccharide $\cdot$ Inflammatory cytokines $\cdot$ Oxidative stress $\cdot$ Euglena tuba

$\begin{array}{ll}\text { Abbreviations } \\ \text { LPS } & \text { Lipopolysaccharide } \\ \text { ETME } & \text { Methanolic extract of Euglena tuba } \\ \text { TBARS } & \text { Thiobarbituric acid reactive substances } \\ \text { SOD } & \text { Superoxide Dismutase } \\ \text { NBT } & \text { Nitroblue tetrazolium } \\ \text { SGPT } & \text { Serum Glutamic Pyruvic Transaminase } \\ \text { SGOT } & \text { Serum Glutamic Oxaloacetic Transaminase } \\ \text { NO } & \text { Nitric oxide } \\ \text { i NOS } & \text { Inducible nitric oxide synthase }\end{array}$

\section{Introduction}

Euglena tuba is an alga that is predominantly found in freshwater ponds, puddles, lakes, and river banks, forming seasonal algal bloom prominently at warm temperatures during

Syed Ibrahim Rizvi sirizvi@gmail.com

1 Department of Biochemistry, University of Allahabad, Allahabad 211002, India conditions of lower dissolved oxygen and acidic environment. Blooms fully cover the pond forming a deep red to greenish coloured continuous layer on the surface of the water (Deb 2015). Various bioactive compounds like phenolics, flavonoids, alkaloids, tannins, terpenoids, saponins, carbohydrates, and ascorbic acid are present in Euglena tuba which provide many documented medicinal properties (Chaudhuri et al. 2014). Studies have shown that Euglena tuba has antioxidant, hepatoprotective, iron-chelator, antitumor activities and can induce apoptosis through ROS- mediated MAPK regulation (Panja et al. 2014, 2016).

Lipopolysaccharide (LPS), an endotoxin, is the key component of the outer membrane of Gram-negative bacteria. The administration of LPS to mice is a widely used strategy to induce an acute systemic inflammatory response. Incorporation of LPS to the body activates an intracellular signaling pathway and causes the production of inflammatory cytokines which are responsible for activating innate immune response by regulating inflammatory mediators such as TNF- $\alpha$, IL-6, and NO (Buras et al. 2005; Schulte et al. 2013). In response to these cytokines, reactive oxygen species are generated from neutrophils and other phagocytic cells which triggers oxidative stress (Sugino et al. 1987). 
Uncontrolled inflammation and excessive oxidative stress may be the leading symptoms of sepsis culminating in multiple organ failure and death (Steven et al. 2017). The symptoms of COVID 19 also show an abnormally high inflammatory response (Zhang et al. 2020).

Based on already available reports that Euglena tuba has excellent anti-inflammatory and antioxidant property, we focus our study to investigate the ameliorative antiinflammatory and antioxidant effect of $70 \%$ methanolic extract of Euglena tuba (ETME) on LPS induced inflammatory response and resultant severe oxidative stress in mice.

\section{Method and material}

\section{Sample collection and characterization}

The algal sample was collected in the month of October from a pond in district Kangra of the state of Himachal Pradesh, India, situated at $28^{\circ} 22^{\prime}$ to $33^{\circ} 12^{\prime} \mathrm{N}, 75^{\circ} 47^{\prime}$ to $79^{\circ} 04^{\prime} \mathrm{E}$ and $31^{\circ} 40^{\prime}-32^{\circ} 25^{\prime}$ East longitudes and $70^{\circ} 35^{\prime}-77^{\circ} 5^{\prime}$ North latitudes. Samples were preserved in $4 \%$ formalin for identification and observed under the light microscope. Morphological features were taken in account and characterized (Kumar et al. 2016).

\section{Extract preparation}

The collected samples were thoroughly cleaned under the sterile condition with distilled water 3-4 times to remove dirt and then centrifuged at $1000 \mathrm{x} g$ to wash out contaminating bacteria. The collected pellet of the biomass of Euglena tuba was dried in sunlight for seven days and then finely powdered. In $100 \mathrm{~mL}$ solvent (methanol: water 7:3) the powder $(10 \mathrm{~g})$ was soaked and stirred for $17 \mathrm{~h}$, then centrifuged at $3000 \mathrm{~g}$. The process was repeated again with the obtained pellet by using a $100 \mathrm{~mL}$ fresh solvent. The total obtained supernatant was concentrated under reduced pressure in a rotary evaporator. The concentrated solution was lyophilized and the $70 \%$ methanolic extract of Euglena tuba (ETME) was obtained which was kept at $-20{ }^{\circ} \mathrm{C}$ for future use.

\section{Animals and experimental design}

6-8 weeks old male Balb/c mice were purchased from the Indian Institute of Toxicological Research, Lucknow, India. The animals were grouped and housed in polyacrylic cages with 6 animals per cage and maintained under standard laboratory conditions. Animals had free access to standard diet purchased from Paramount Techno Company and water ad libitum. Animals were randomly divided into four groups, each comprising six animals. Group 1 the controls were intraperitoneally administered $0.5 \mathrm{~mL}$ PBS. Group 2,3 and 4 were treated with a single dose of LPS (O55: B5 E.coli purchased from Sigma Aldrich, Mumbai) (i.p. $40 \mathrm{mg} / \mathrm{kg}$ body weight) (Lee et al. 2013). Prior $1 \mathrm{~h}$ Group 3 and 4 received orally $100 \mathrm{mg} / \mathrm{kg}$ body weight and $200 \mathrm{mg} / \mathrm{kg}$ body weight ETME respectively. Blood samples were drawn $3 \mathrm{~h}$ after LPS treatment from orbital sinus and plasma was separated. The survival of the mice was monitored for 5 days and sacrificed by cervical dislocation. All experiments using mice were done in accordance with the guidelines of the Institutional Ethical Committee (839/GO/Re/04/CPCSEA).

\section{Nitric oxide (NO)}

Nitric oxide levels was measured in the plasma by Griess reaction (Yamamoto et al. 1998). The samples were incubated with Griess reagent $(0.1 \%$ naphthalene diamine $\mathrm{HCl} ; 1 \%$ sulfanilamide in 5\% phosphoric acid mixed as 1:1) and the pinkcolored product thus formed was measured at $540 \mathrm{~nm}$ on a spectrophotometer. Production of Nitric oxide was calculated by comparing standard sodium nitrite conc. and the results are expressed as $\mu \mathrm{mol} / \mathrm{L} \mathrm{NO}$.

Total protein content was estimated in plasma samples by using the method of Lowry et al. (1951).

\section{Estimation of cytokine level (IL- 6 and TNF $-a$ ) in the serum of mice}

Cytokine levels were estimated following the directions given as per the manufacturer's manual (Krishgen Bio framework, India) as described previously in detail (Kumar et al. 2020). The result is reported in $\mathrm{Pg} / \mathrm{mL}$.

\section{Thiobarbituric acid reactive substances (TBARS)}

Malondialdehyde (MDA) in plasma was determined by reaction with thiobarbituric acid (TBA) (Buege and Aust 1978). Briefly; $0.1 \mathrm{~mL}$ Tris -HCL buffer, $0.1 \mathrm{~mL}$ Ferrous sulphate and $0.1 \mathrm{~mL}$ Ascorbic acid. $0.05 \mathrm{~mL}$ sample was added and the volume was made up to $1.0 \mathrm{~mL}$ with DDW. $1.0 \mathrm{~mL}$ TCA and $2 \mathrm{~mL}$ TBA were added after incubation at $37^{\circ} \mathrm{C}$ for $15 \mathrm{~min}$. Tubes were plugged and incubated for $15 \mathrm{~min}$. in a boiling water bath. After incubation, tubes were centrifuged at $3000 \mathrm{rpm}$ for $10 \mathrm{~min}$. and the supernatant was read at $532 \mathrm{~nm}$. The concentration of MDA was calculated using the extinction coefficient of $1.56 \times 10^{5} \mathrm{M}^{-1} \mathrm{~cm}^{-1}$. Results are expressed as nmol MDA/mg protein.

\section{Superoxide dismutase (SOD)}

The activity of the enzyme superoxide dismutase was determined according to the method of Kono (1978). Auto oxidation of hydroxylamine HCL generates superoxide anions. These anions bring about the reduction of NBT to blue 
formazone. SOD inhibits the reduction of NBT induced by hydroxylamine HCL. The activity of the enzyme was expressed as units/mg protein, where one unit of enzyme is defined as the amount of enzyme inhibiting the rate of reaction by $50 \%$.

\section{Catalase}

Catalase activity was assayed by the method of Luck (1971). Catalase is an enzyme that catalyzes the decomposition of hydrogen peroxide to oxygen. The rate of decomposition of hydrogen peroxide is assessed spectrophotometrically at $240 \mathrm{~nm}$. The activity of the enzyme is expressed as $\mu$ moles of hydrogen peroxide decomposed per min per mg protein, using the molar extinction coefficient of hydrogen peroxide $\left(71 \mathrm{M}^{-1} \mathrm{~cm}^{-}{ }^{1}\right.$ ).

\section{Measurement of liver marker enzyme}

Determination of serum SGPT, and SGOT level was performed using reagent kits from Span diagnostic and ERBA diagnostics and measurements were made on an Erba Mannheim Chem.-7 analyzer.

\section{Statistical analysis}

All data are expressed as mean $\pm \mathrm{SD}$ of six measurements and statistical analysis was performed using GraphPad Prism 7.04 software. Data were analyzed by one-way ANOVA. A probability of $P<0.05$ was considered significant.

\section{Results}

\section{Nitric oxide}

Figure 1 shows levels of NO in plasma of all groups. The NO levels were found to be significantly $(p<0.05)$ higher in the

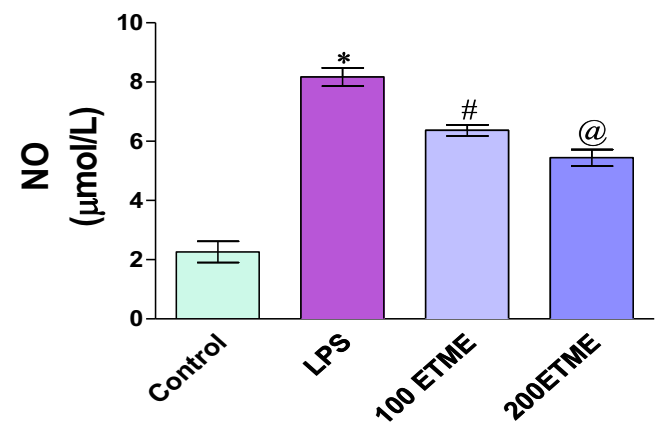

Fig. 1 Effect of different doses of ETME on the level of NO in LPS induced oxidative stress. ${ }^{*} p<0.05$ significant changes occurs between 100 ETME to the LPS group, @ represent significant $p<0.05$ change occurs between 200 ETME compared to the LPS group
LPS group with respect to control group while significant decreases $(p<0.05)$ were seen in the ETME group as compared to the LPS group.

\section{Cytokine level (IL- 6 and TNF $-a$ ) in the serum of mice}

Cytokine levels are represented in Fig. 2a and b. The activity of both cytokines is significantly $(p<0.05)$ increased in LPS treated groups of mice with respect to control. A significant reduction is seen in both ETME groups of mice when compared with LPS group.

\section{Thiobarbituric acid reactive substances}

Lipid peroxidation is one of the important oxidative stress markers measured in the form of MDA and value is reported in the form of $\mathrm{nmol} / \mathrm{mg}$ protein. According to variously reported studies lipid peroxidation increases with oxidative stress. Our result also confirms increase in the level of lipid peroxidation in the LPS group as compared to control whereas both ETME groups show significant $(p<0.05)$ decrease in the MDA level with respect to LPS group Fig. $3 a$.

\section{Superoxide dismutase}

Figure 3b, shows the SOD activity. Significantly increased $(p<0.05)$ value of SOD are found in the LPS group as compared to control, whereas both ETME groups show significant $(p<0.05)$ decrease in the SOD level with respect to LPS group.

\section{Catalase}

Catalase is one of the important antioxidant biomarkers markers. Figure 3c, represents the level of catalase activity. In the LPS group of mice, there was $(p<0.05)$ significantly decrease in the level of enzyme activity with respect to the control group of mice while significantly increased $(p<0.05)$ in the enzyme activity are found in $100 \& 200$ ETME groups when compared to the LPS group. 200 ETME supplementation provides a better result with respect to 100 ETME.

\section{Serum SGPT and SGOT level}

SGOT and SGPT level are shown in Fig. 4a and b. The activity of both markers is significantly $(\mathrm{p}<0.05)$ increased in LPS treated groups of mice with respect to control. A significant reduction is seen in both ETME groups of mice when compared with LPS group. 
Fig. 2 and $b$ represents the cytokine level in mice serum.*, \# and @ represent the significant increase $(p<0.05)$ in the value of cytokines with respect to their control LPS and different concentration of ETME supplementation (a)

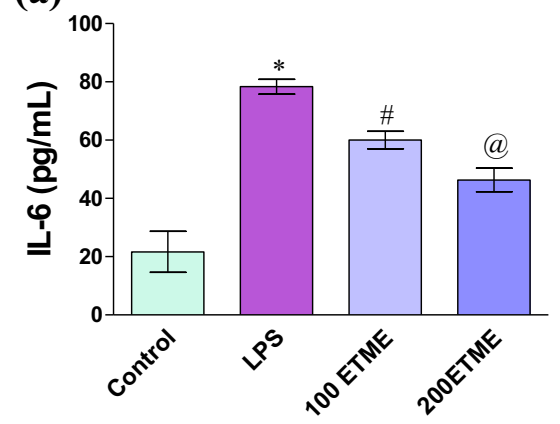

(b)

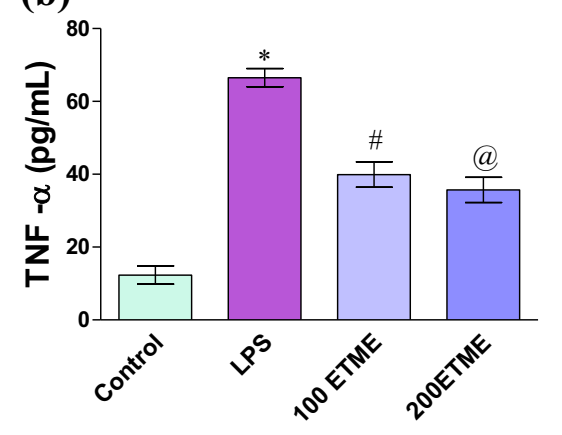

\section{Discussion}

Microalgae are the best antioxidants used in different pathologies related to the generation of free radicals associated with several diseases (Sathasivam et al. 2019). Antioxidant properties of frequently consumed food, vegetables, and other herbs have been confirmed as a good source of potent antioxidant due to their phytochemicals (Proteggente et al. 2002). Polyphenols and flavonoids are strong antioxidants that can act as reducing agent (Karaman et al. 2010), free radical scavengers (Kähkönen et al. 1999), inhibitors of lipid peroxidation (Williams et al. 2004) and thereby preventing oxidative damage (Ross and Kasum 2002). HPLC analysis of Euglena tuba extract corroborate the presence of bioactive compounds including tannic acid,reserpine, methyl gallate, catechin, ascorbic acid and rutin, the presence of these compounds validate the strong antioxidant property of ETME (Chaudhuri et al. 2014). Moreover GC-MS analysis of ETME also showed the presence of compounds such as isovanillin, 3-hydroxy-5methoxy benzaldehyde, $\alpha$-D-glucopyranoside, methyl-2,6-dihydroxy-4-methyl benzoate, methyl palmitate, 14,17octadecadienoic acid, and viminalol which may contribute to antioxidant, antiperoxidative, anti-inflammatory and anticancer activities (Panja et al. 2014).

Overproduction of free radicals increases the level of oxidants which is the underlying mechanism of oxidative damage. Excessive oxidative stress is a distinguishing aspect of LPS. Therapies targeting redox abnormalities could be useful for improving the management of sepsis. Studies have revealed that prolonged vascular inflammation and oxidative stress in response to infection or endotoxin (LPS) induction is a distinct trait related to sepsis (Steven et al. 2017). The

(b)

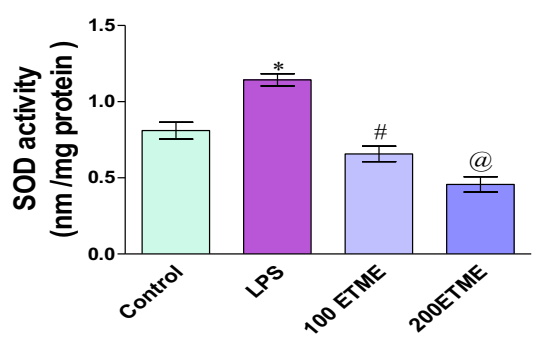

(c)

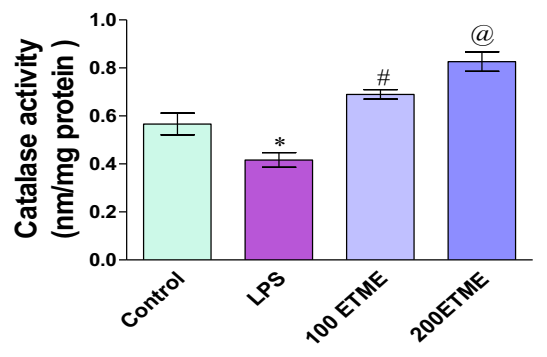

Fig. 3 a Effect of different doses of ETME on the level of MDA in LPS induced oxidative stress. $p<0.05$ compared to the control group, \# $p<0.05$ significant changes occurs between 100 ETME to the LPS group, @ represent significant $p<0.05$ change occurs between 200 ETME compared to the LPS group. b Effect of different doses of ETME on the SOD enzyme in LPS induced oxidative stress. ${ }^{*} p<0.05$ compared to the control group, ${ }^{\#} p<0.05$ significant changes occurs between 100 ETME to the LPS group, @ represent significant $p<0.05$ change occurs between 200 ETME compared to the LPS group. $\mathbf{c}$ Effect of different doses of ETME on the catalase enzyme in LPS induced oxidative stress. $p<0.05$ significant changes occurs between 100 ETME to the LPS group, @ represent significant $p<0.05$ change occurs between 200 ETME compared to the LPS group 
Fig. 4 a and $b$ The serum SGPT and SGOT are represented are in Fig. 2.*,\# and @ represent the significant increase $(p<0.05)$ between control, LPS and different concentration of ETME supplementation (a)

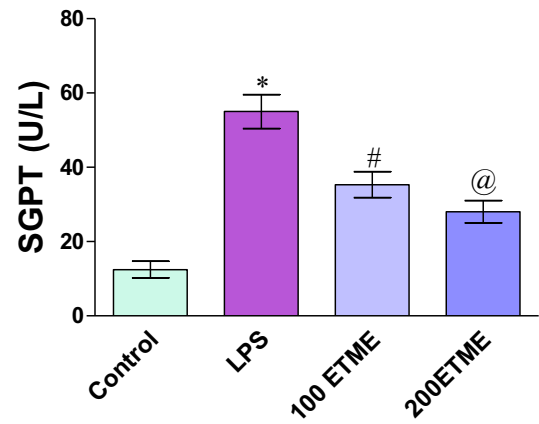

(b)

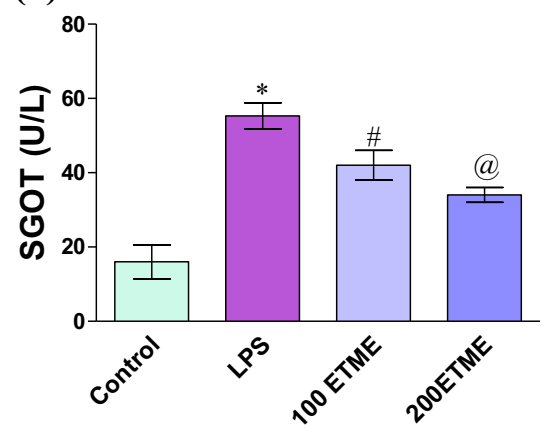

antioxidant defense system of the body involves a range of antioxidants and enzymes such as SOD, CAT, GST, and GSH. Our results provide evidence that the administration of LPS alters the level of antioxidant enzymes and that oral administration of the Euglena tuba extract can provide protection against oxidative stress. ETME shows in vitro hydroxyl radical scavenging activity that can eliminate hydroxyl radical and significantly decrease the level of lipid peroxidation, suggesting that may ETME function as a good antioxidant that can effectively reduce the cellular toxicity of LPS (Chaudhuri et al. 2014).

A high level of SOD and low level of Catalase is an adaptive response to increased oxidative damage created due to the administration of endotoxin LPS (Portolés et al. 1996). Our result suggests that ETME shows superoxide radical scavenging activity that might be due to the presence of flavonoids which effectively scavenge superoxide anions (Sunil et al. 2011). However, the level of Catalase significantly increases by the action of phenolics linked to enzymatic and nonenzymatic reactions of antioxidants (Nirmal et al. 2008).

The development of reactive oxygen and nitrogen species is an important part of the innate immune response. High level of NO is generated by i-NOS after induction by any pathogen, cytokines, growth factors and endotoxin which plays a significant role in the pathology of several diseases such as arthritis, diabetes, atherosclerosis, and sepsis (Nathan 1992; Nussler and Billiar 1993). The overproduction of NO is the characteristic feature of endotoxin. LPS induction enhances the expression of i-NOS that consequently activates the nuclear factor $(\mathrm{NF}-\mathrm{KB})$ and increases the production of $\mathrm{NO}$ (Virdis et al. 2005). However, ETME reduces the toxicity of NO due to the presence of anti-inflammatory compounds which might inhibit nitrite formation by directly competing with oxygen in the reaction with nitric oxide (Chaudhuri et al. 2014).

The liver is the main organ of oxidative and detoxifying action. During stress conditions increase in the amount of ROS and inflammation plays an important role in altering the liver function markers SGOT and SGPT. Our results show increase in the level of both marker enzymes in the LPS treated group of mice whereas the different concentration of ETME reversed this effect, higher conc. of ETME provides better results, so our finding support that the ETME supplement reduced ROS and inflammation and also work as a hepatoprotective compound.

Our findings assume great significance in present times when science is trying to find ways to limit the mortality caused by COVID 19. The major cause of multiple organ failure in patients of COVID 19 is due to the production of very high levels of pro-inflammatory cytokines which is referred to as 'cytokine storm' (Sallard et al. 2020; Stebbing et al. 2020). Our results show that ETME may reduce the level of LPS induced cytokines thus providing an intervention strategy for the management of COVID 19.

\section{Conclusion}

Our finding demonstrates that $70 \%$ methanolic extract of Euglena tuba can efficiently counteract free radical generation and increased level of pro-inflammatory cytokine in an LPS induced mice model. The outcome of this study strongly suggests that the extract of Euglena tuba can be used as a therapeutic agent to reduce the risk of systemic inflammation and oxidative stress in chronic diseases. The results may also provide a line of defense for COVID 19.

Acknowledgments We would like to thank Dr. Rakesh Kumar for collection of Euglena samples.

Financial support This work was supported by a research grant from SERB-DST, Govt. of India (EMR/2016/006470).

Data availability The information that helps the finding of this study is accessible from the corresponding author upon reasonable request.

\section{Compliance with ethical standards}

Ethics approval All experiments using mice were done in accordance with the guidelines of the Institutional Ethical Committee $(839 / \mathrm{GO} / \mathrm{Re} /$ 04/CPCSEA).

Conflict of interest The authors of this manuscript have no conflict of interest. 


\section{References}

Buege JA, Aust SD (1978) Microsomal lipid peroxidation. In Methods in enzymology 52:302-310. Elsevier. https://doi.org/10.1016/S0076$6879(78) 52032-6$

Buras JA, Holzmann B, Sitkovsky M (2005) Animal models of sepsis: setting the stage. Nat Rev Drug Discov 4(10):854-865. https://doi. org $/ 10.1038 /$ nrd 1854

Chaudhuri D, Ghate N, Deb S, Panja S, Sarkar R, Rout J, Mandal N (2014) Assessment of the phytochemical constituents and antioxidant activity of a bloom forming microalgae Euglena tuba. Biol Res 47(1):24. https://doi.org/10.1186/0717-6287-47-24

Deb S (2015) Morphology and biochemical study of a microalga Euglena tuba reported from the aquatic ecosystem of cachar. Res Rev J Pharmacog Phytochem 3:1-10

Kähkönen MP, Hopia AI, Vuorela HJ, Rauha JP, Pihlaja K, Kujala TS, Heinonen M (1999) Antioxidant activity of plant extracts containing phenolic compounds. J Agric Food Chem 47(10):3954-3962. https://doi.org/10.1021/j99901461

Karaman S, Tütem E, Baskan KS, Apak R (2010) Comparison of total antioxidant capacity and phenolic composition of some apple juices with combined HPLC-CUPRAC assay. Food Chem 120(4):12011209. https://doi.org/10.1016/j.foodchem.2009.11.065

Kono Y (1978) Generation of superoxide radical during autoxidation of hydroxylamine and an assay for superoxide dismutase. Arch Biochem Biophys 186(1):189-195. https://doi.org/10.1016/00039861(78)90479-4

Kumar R, Toppo K, Mandotra SK, Suseela MR, Seth MK, Minhas U, Kesherwani R, Gupta SP (2016) Quantitative analysis and first report of Euglena tuba from Himachal Pradesh, India. IJSR 5(12): 1336-1339

Kumar R, Akhtar F, Rizvi SI (2020) Hesperidin attenuates altered redox homeostasis in an experimental hyperlipidaemic model of rat. Clin Exp Pharmacol Physiol 47(4):571-582. https://doi.org/10.1111/ 1440-1681.13221

Lee MH, Kang H, Lee K, Yang G, Ham I, Bu Y, Kim H, Choi HY (2013) The aerial part of Taraxacum coreanum extract has an antiinflammatory effect on peritoneal macrophages in vitro and increases survival in a mouse model of septic shock. J Ethnopharmacol 146(1):1-8 https://linkinghub.elsevier.com/ retrieve/pii/S0378874112008434

Lowry OH, Rosebrough NJ, Farr AL, Randall RJ (1951) Protein measurement with the Folin phenol reagent. J Biol Chem 193:265-275

Luck H. (1971) Catalase. In: Hu, B, Ed, Methods of Enzymatic Analysis 3:279

Nathan C (1992) Nitric oxide as a secretory product of mammalian cells. FASEB J 6(12):3051-3064. https://doi.org/10.1096/fasebj.6.12. 1381691

Nirmal J, Babu CS, Harisudhan T, Ramanathan M (2008) Evaluation of behavioural and antioxidant activity of Cytisus scoparius link in rats exposed to chronic unpredictable mild stress. BMC Complement Altern Med 8(1):15. https://doi.org/10.1186/1472-6882-8-15

Nussler AK, Billiar TR (1993) Inflammation, immunoregulation, and inducible nitric oxide synthase. J Leukoc Biol 54(2):171-178. https://doi.org/10.1002/jlb.54.2.171

Panja S, Chaudhuri D, Ghate NB, Mandal N (2014) Phytochemical profile of a microalgae Euglena tuba and its hepatoprotective effect against iron-induced liver damage in Swiss albino mice. J Appl Microbiol 117(6):1773-1786. https://doi.org/10.1111/jam.12643

Panja S, Ghate NB, Mandal N (2016) A microalga, Euglena tuba induces apoptosis and suppresses metastasis in human lung and breast carcinoma cells through ROS-mediated regulation of MAPKs. Cancer Cell Int 16(1):13. https://doi.org/10.1186/s12935-016-0330-5
Portolés MT, Catalá M, Antón A, Pagani R (1996) Hepatic response to the oxidative stress induced by E. coli endotoxin: glutathione as an index of the acute phase during the endotoxic shock. Mol Cell Biochem 159(2):115-121. https://doi.org/10.1007/BF00420913

Proteggente AR, Pannala AS, Paganga G, Buren Lv, Wagner E, Wiseman S, van de PF, Dacombe C, Rice-Evans CA (2002) The antioxidant activity of regularly consumed fruit and vegetables reflects their phenolic and vitamin $\mathrm{C}$ composition. Free Radic Res 36(2):217-233. https://doi.org/10.1080/10715760290006484

Ross JA, Kasum CM (2002) Dietary flavonoids: bioavailability, metabolic effects, and safety. Annu Rev Nutr 22(1):19-34. https://doi.org/ 10.1146/annurev.nutr.22.111401.144957

Sallard E, Lescure FX, Yazdanpanah Y, Mentre F, Peiffer-Smadja N, Florence A (2020) Type 1 interferons as a potential treatment against COVID-19. Antivir Res 178:4. https://doi.org/10.1016/j.antiviral. 2020.104791

Sathasivam R, Radhakrishnan R, Hashem A, Abd Allah EF (2019) Microalgae metabolites: a rich source for food and medicine. Saudi Journal of Biological Sciences 26(4):709-722. https://doi. org/10.1016/j.sjbs.2017.11.003

Schulte W, Bernhagen J, Bucala R (2013) Cytokines in sepsis: potent immunoregulators and potential therapeutic targets - an updated view. Mediat Inflamm 2013:16. https://doi.org/10.1155/2013/ 165974

Stebbing J, Phelan A, Griffin I, Tucker C, Oechsle O, Smith D, Richardson P (2020) COVID-19: combining antiviral and antiinflammatory treatments. Lancet Infect Dis 20(4):400-402

Steven S, Dib M, Roohani S, Kashani F, Münzel T, Daiber A (2017) Time response of oxidative/nitrosative stress and inflammation in LPS-induced endotoxaemia - a comparative study of mice and rats. Int J Mol Sci 18(10):12. https://doi.org/10.3390/ijms18102176

Sugino K, Dohi K, Yamada K, Kawasaki T (1987) The role of lipid peroxidation in endotoxin-induced hepatic damage and the protective effect of antioxidants. Surgery 101(6):746-752. https://doi.org/ 10.5555/uri:pii:0039606087900894

Sunil AG, Kesavanarayanan KS, Kalaivani P, Sathiya S, Ranju V, Priya RJ, Pramila B, Paul FS, Venkhatesh J, Babu CS (2011) Total oligomeric flavonoids of Cyperus rotundus ameliorates neurological deficits, excitotoxicity and behavioral alterations induced by cerebral ischemic-reperfusion injury in rats. Brain Res Bull 84(6):394 405. https://doi.org/10.1016/j.brainresbull.2011.01.008

Virdis A, Colucci R, Fornai M, Blandizzi C, Duranti E, Pinto S, Bernardini N, Segnani C, Antonioli L, Taddei S (2005) Cyclooxygenase-2 inhibition improves vascular endothelial dysfunction in a rat model of endotoxic shock: role of inducible nitricoxide synthase and oxidative stress. J Pharmacol Exp Ther 312(3): 945-953. https://doi.org/10.1161/01.HYP.0000253085.56217.11

Williams RJ, Spencer JP, Rice-Evans C (2004) Flavonoids: antioxidants or signalling molecules? Free Radic Biol Med 36(7):838-849. https://doi.org/10.1016/j.freeradbiomed.2004.01.001

Yamamoto K, Akbar SKMDF, Masumoto O (1998) Increased nitric oxide (NO) production by antigen-presenting dendritic cells is responsible for low allogeneic mixed leucocyte reaction (MLR) in primary biliary cirrhosis (PBC). Clin Exp Immunol 114(1):94-101

Zhang R, Wang X, Ni L, Di X, Ma B, Niu S, Liu C, Reiter RJ (2020) COVID-19: melatonin as a potential adjuvant treatment. Life Sci 250:6. https://doi.org/10.1016/j.lfs.2020.117583

Publisher's note Springer Nature remains neutral with regard to jurisdictional claims in published maps and institutional affiliations. 